Volume 8, No.5, September - October 2019

International Journal of Advanced Trends in Computer Science and Engineering

Available Online at http://www.warse.org/IJATCSE/static/pdf/file/ijatcse58852019.pdf

https://doi.org/10.30534/ijatcse/2019/58852019

\title{
Effects of Tribotechnical composition, Engine oil, and Iso-octane on samples of Elastomers of Automobile Technology in Aviation Industry
}

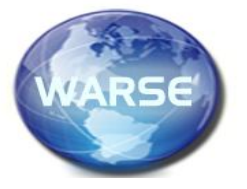

\author{
Alexey V. Azanov ${ }^{1}$, Aleksey G. Amosov ${ }^{2}$, Sergey V. Khlopkov ${ }^{3}$, Alexander A. Khodyakov ${ }^{4}$
}

${ }^{1}$ Post-graduate student of the Department of mechanical engineering and instrument engineering, engineering Academy, The Peoples' Friendship University of Russia, Russia, aav-26.02@yandex.ru

${ }^{2}$ Assistant of the Department 904, Moscow aviation Institute (national research University), Russia, lamosov@ yandex.ru

${ }^{3}$ Assistant of the Department of mechanical engineering and instrument engineering, engineering Academy, The Peoples' Friendship University of Russia, Russia, aav-26.02@yandex.ru

${ }^{4}$ Candidate of chemical Sciences, associate Professor, Department of mechanical engineering and instrument engineering, engineering Academy, The Peoples' Friendship University of Russia, Russia, aav-26.02@ yandex.ru

\begin{abstract}
The article is devoted to the actual problem of wear resistance of elements of motor vehicles from the composition of aviation industry. As a research task, the authors determined an attempt to evaluate and analyze the effects of aggressive media on elastomers. The characteristic features of the current approach to the description of this process are also highlighted and described. In a process of engine operation, the base additives presented in engine oil "wear off", engine oil compositions change. The tribotechnical composition which used for gasoline engines has not only a washing effect (i.e. it removes carbone deposits and sediments from the surfaces of the powertrain parts), but it is also forms a wearresistant layer on the metal surface with a low friction coefficient. This ability of the tribotechnical composition (TC) is related to the sheet silicates which are the part of the structure (the active component is superdispersed particles of serpentines, chlorites and other minerals). According to literary sources, the sheet silicates are chemically neutral to all substances from the lubricant additives.
\end{abstract}

Key words: Aviation industry, automotive equipment, tread elastomer, aggressive environment.

\section{INTRODUCTION}

The modern aviation industry consists not only of airplanes and aircraft, but also of automobiles used for various purposes. In order to guarantee the stable functioning of automotive equipment, for example, ensuring the flight safety, units entering into automobiles, units and parts must possess high reliability and resource. One of the ways to improve reliability is the use of rubber products (elastomers, polymers) of a new generation, taking into account the constantly changing conditions of vehicle functioning.

The problem of elastomer failure is solved by replacement. However, the frequency of replacement of rubber products (RRP) leads to increased requirements for quality of repair and cost of work. Therefore, in order to increase the service life (reduce the frequency of replacement), RRP must be studied in terms of the effect on cyclic loads, aggressive media, and natural aging on elastomers.

It should be noted that due to the low cost of rubber products used in mechanical engineering, little attention is paid to the study of the aging process and the swelling of elastomers in aggressive media.

Such items as car tires, as well as rubber-containing lip seals (oil seals) and oil scraper caps (valve seals), function under the conditions of exposure of a specified material to multiple cyclic loads and temperatures. Over time, as a result of the action of these loads and heat, rubber (which refers to macro-chain polymers) is aging, losing its elasticity [1-3].

Cyclic loads have a negative effect on the performance of polymers (high-molecular compounds) [3]. The polymer, being under cyclic loads, get quickly warmed up. Heat, due to the low thermal conductivity of the polymer, accumulates in its volume and does not dissipate into the environment. Increasing the temperature of the polymer reduces the strength properties of the product as a whole. A similar effect associated with exposure to intramolecular bonds and bonds between segments of different macromolecules is also characteristic of the mechanical load itself [3].

To improve the physicomechanical properties of automobile tires and seals, they were injected with various substances that affect the elastic-strength properties and wear resistance [4], [5]. They also investigate the reliability of tires and control the tightness of lip seals [6], [7].

With repeated deformations of seals, glands in contact with oils during operation, because of the process of swelling that occurs during the contact of rubber with liquid, not only an increase in the mass and volume of the rubber product (RRP), shape of the material, but also the decrease of elasticity wear resistance and hardness were observed [4], [8]. Therefore, the study of the process of swelling of rubber, which is at different stages of quality degradation, is relevant. This is relevant from the point of view of the modern trend of creating high-quality rubber products based on various fillers [5]. 


\section{MATERIALS AND METHODS}

Samples of radial tire tread (Barum 155/70 R13 75T Brillantis 2) with dimensions of not more than $2 \cdot 10^{-2} \times 1.5 \cdot$ ${ }^{2} \times 5 \cdot 10^{-3}[\mathrm{~m}]$, samples of the sealant (gland; type 2108170342-01) in the shape of a semicircle with the size of $2.7 \cdot 10^{-2} \times 7 \cdot 10^{-3} \times 2 \cdot 10^{-3}[\mathrm{~mm}]$ were held.

Both the original and aged rubber samples were studied. Aging was carried out in the stream of air pumped forcibly through a reactor with rubber placed into it. The heat treatment time was 12-100 hours, the temperature was $70-150^{\circ} \mathrm{C}$. Such an organization of the experiments is connected with the fact that rubber, annealed, for example, at $70^{\circ} \mathrm{C}$ for 144 hours, is similar in properties to a material that has undergone natural aging for 3 years. The change in the properties of rubber was evaluated by the parameter of change in the mass of the samples (original and aged) after their contact with the liquid.

The rubber, previously weighed on the VLTE-150 portion scales, was placed in the liquid samples, then, after a certain period of time, the mass of the samples was monitored after their contact with the liquids. The maximum permissible error of the weights is $\pm 0.003 \mathrm{~g}$, the standard deviation is $0.0015 \mathrm{~g}$.

The experiments were carried out at $20-80^{\circ} \mathrm{C}$, stirring a liquid with a magnetic stirrer with rubber samples placed in it. In the presented test method, the features of the methods used to determine the resistance of rubber to liquids and to study the kinetics of rubber swelling were taken into account [4; 8-10]. Iso-octane (2,2,4trimethylpentane), engine oil (EO) "GENESIS CLARITECH" 5W-30, tribological composition (TC) "ACTIVE PLUS" ("suprotec") were used as a liquid.

The kinematic viscosity of the EO and TC was determined (in the temperature range from $20^{\circ} \mathrm{C}$ to $100^{\circ} \mathrm{C}$ ) with VPJ-4 viscometers, the density $(\rho)$ of the liquids was measured with oil densimeters.

The calculation of viscosity $(v, c C t)$ was carried out according to the equation:

$$
\nu=C \cdot \tau
$$

where $\mathrm{C}$ is a constant viscometer, $\mathrm{cCt} \cdot \mathrm{c}^{-1}$; $\tau$ is the arithmetic mean time of fluid sample outflow, (in seconds).

The calculation of the viscosity index (VI) of the motor oil and TC was performed using an online calculator.

The hardness of rubber specimens was evaluated by measuring the resistance of rubber to the immersion (springloaded rod) immersed in it. A dial gauge type IH-02 (accuracy class 0) was used as a measurement [8].

\section{RESULTS}

As a result of the conducted research, it was established that the mass of the available original and, as a consequence of the experiment, aged rubber samples after their contact with the liquids increases.

The resulted growth of the mass of the starting material obtained during the experiment is associated with the absorption of the solvent (liquid molecules) by a highmolecular substance, that is, due to the swelling of the macroreticular polymer.

The hardness of the aged material increases in comparison with the hardness of the original rubber. This is due to the increase in the frequency of cross-links, which reduces the flexibility of the chains of macromolecules and, accordingly, the number of resulting (as a result of thermal motion), commensurate with the size of molecules of liquids, small intermolecular spaces.

\section{DISCUSSION}

In Table 1, the degree of swelling of the samples of the initial tire (IC), samples of the aged (for 90 hours at $150^{\circ} \mathrm{C}$; ASP) and initial (IC) seal are shown. The calculation of the degree of swelling $(\alpha)$ was given by the equation [4]:

$$
\alpha=\frac{m-m_{0}}{m_{0}}
$$

where $m$ is the mass of the swollen polymer, $\mathrm{g} ; m_{0}$ is the mass of the original sample before swelling, $\mathrm{g}$.

From a comparison of the data (Table 1), it follows that the parameter $\alpha$ for the tire tread sample is higher than the degree of swelling of the rubber seal. The results obtained are quite natural, since the tire tread rubber has a slightly different composition than the seal.

An aged seal pattern swells less than SOS. This is explained by the fact that ASP, in contrast to the original rubber, after exposure to heat it lost its elasticity completely, turned into a solid monolith. Undoubtedly, such a transition and, as a consequence, a significant change in the structure of the polymer is reflected in the ability of the aged sealer to swell. An aged tire sample (similar to a compactor) swells to a lesser extent than the original material (Table 1).

Table 1: The degree of swelling $(\alpha)$ of the rubber samples in

\begin{tabular}{|c|c|c|c|c|c|c|}
\hline \multirow[b]{2}{*}{$\begin{array}{l}\text { of } \\
\text { min }\end{array}$} & \multirow{2}{*}{$\begin{array}{l}\text { Time } \\
\text { contact, }\end{array}$} & \multicolumn{3}{|c|}{$\alpha$, rel.m. } & \multirow[b]{2}{*}{${ }^{* * * * * *} \mathbf{A}$} & \multirow[b]{2}{*}{ OS } \\
\hline & & 1 & ${ }^{*} \mathbf{S}$ & $\mathbf{T} \quad{ }^{* * *} \mathbf{A}$ & & \\
\hline & 200 & 1 & 0.1 & ---- & ---- & ---- \\
\hline & 300 & 7 & & & ---- & --- \\
\hline & 500 & 1 & 0.2 & $\begin{array}{ll} & 0.0 \\
9 & \end{array}$ & $10^{-3} \quad$ 8.6. & 0.02 \\
\hline
\end{tabular}
iso-octane at $20^{\circ} \mathrm{C}$

Figure 1 shows the change in mass $(\Delta \mathrm{m})$ of the liquid remaining in the tire tread after the sample was in contact with iso-octane for 300 minutes. The parameter $\Delta \mathrm{m}$ does not depend on time linear. $85 \%$ of iso-octane is extracted from the tire tread at $20^{\circ} \mathrm{C}$ to the atmosphere in 135 minutes of storage. The same time for the sealer to extract the liquid was only 30 minutes. The low time of extraction of isooctane from rubber indicates that liquid molecules penetrate the volume of the samples shallowly.

Table 2 presents the results of testing samples of the original and aged (within 90 hours) tires. The average time of contact of the objects with the liquid was 426 minutes. The experiments with motor oil and TC were carried out at $80^{\circ} \mathrm{C}$. 


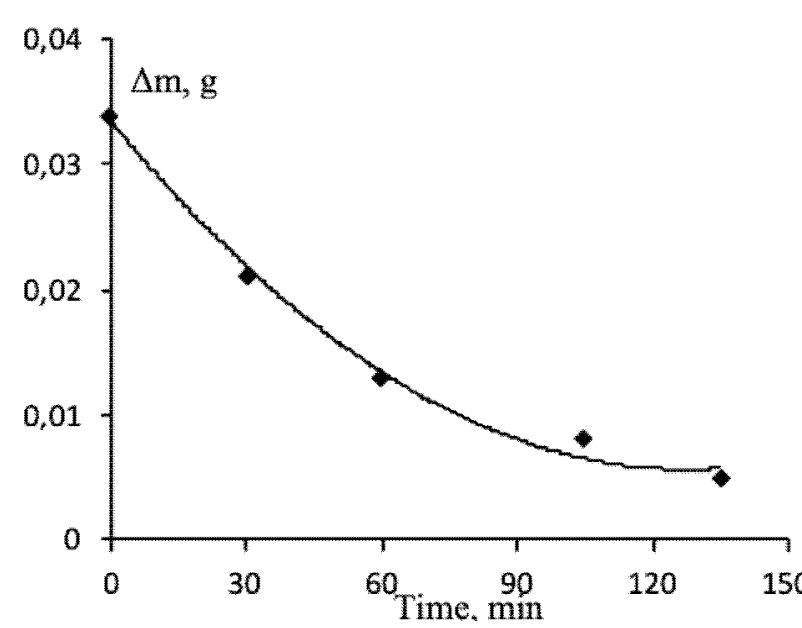

Figure 1: The change in mass $(\Delta \mathrm{m})$ of iso-octane remaining in the tread of the original tire depending on the sample storage time.

Table 2: The degree of swelling $(\alpha)$ of tire tread samples in engine oil (EO), the tribological composition (TC) and EO, containing $0.8 \%$ of the vehicle at $80^{\circ} \mathrm{C}$

\begin{tabular}{|c|l|l|}
\hline \multirow{2}{*}{ Liquid } & \multicolumn{2}{|c|}{ ST rel.m. } \\
\hline EO & 0.10 & AT \\
\hline TC & 0.20 & 0.03 \\
\hline $\begin{array}{c}\text { TS (0.8\% of } \\
\text { mass) + MM (99.2\% } \\
\text { of mass.) }\end{array}$ & ---- & 0.06 \\
\hline
\end{tabular}

From a comparison of the data (Table 2), it follows that, as in the case of iso-octane, the degree of swelling of the original tire tread samples was higher than the parameter $\alpha$ of the aged material. The degree of swelling of the tread in the engine oil was below $\alpha$ and obtained for samples in contact with the TC. In the samples of the sealant, the effect of swelling after contact of the material for 426-00 min with engine oil and "suprotec" was not observed.

After annealing it for 90 hours, the compactor, unlike the aged tire tread pattern, completely lost its elasticity. However, as it follows from the data (Table 1), aged rubber behaves in the same way to isooctane, i.e. it swells to a lesser extent than the original samples. This indicates that changes in the structure of the seal and the tire tread under the action of heat are identical. Therefore, the data on swelling obtained for the tire tread samples can be extended to the seal rubber.

The use of the tribotechnical composition as a test fluid for rubber was motivated by the goal of evaluating the chemical activity of the "super-protein" when used in engines operating under high loads on the cylinder-piston group, crank mechanism, valve timing mechanism, and lubrication system.

Studies conducted at the Naval Academy of N.G. Kuznetsov, showed positive changes in the performance of the internal combustion engine operating on lubricant (engine oil) containing "suprotec" [11]. At the same time, there is no information on the study of the TC effect on the properties of RRP located in the engine, which nodes at different stages of quality degradation. At the same time, it is known that the degree of swelling of rubber is related to the chemical composition of motor oil. Therefore, experiments were carried out with the «suprotec».

From a comparison of the data (Table 2), it follows that the degree of swelling of the aged tire tread after its contact with engine oil is lower than the parameter $\alpha$ obtained for the sample in contact with the vehicle. In engine oil containing $0.8 \%$ (mass.) "suprotec" the degree of swelling is identical to the $\alpha$ of the sample in contact with EO. Consequently, the obtained $\alpha$ value for the samples after contact with the "suprotec" is not related to the fine particles of layered silicates present in the vehicle, but is determined by the chemical composition of the dispersion medium (base material of the TC), i.e. oil. Indeed, as it follows from the data (Table 3), the indicators of the base material of the TC - oils differ from the values of $v, \rho$, and $50 \mathrm{VI}$ of engine oil. The maximum differences are observed in the values of viscosity at $100^{\circ} \mathrm{C}$ and VI. So, $v$ of engine oil at the specified temperature is higher than the viscosity of the vehicle by $\sim 30 \%$.

Table 3: The values of viscosity, density, VI, activation energy of viscous flow of the original engine oil (EO) and tribological composition (TC)

\begin{tabular}{|c|c|c|}
\hline Parameter & TC & EO \\
\hline $\begin{array}{l}\quad v \text { under } 40^{\circ} \mathrm{C}, \\
\mathrm{cC} \text { T }\end{array}$ & 62.2 & $68.65^{*}$ \\
\hline $\begin{array}{cc}v & \text { under } \\
100^{\circ} \mathrm{C}, \mathrm{cC} \text { T } & \\
\end{array}$ & 7.7 & $11.23^{* *}$ \\
\hline VI & 84 & $169^{* * *}$ \\
\hline$\rho_{15}, \mathrm{~kg} \cdot \mathrm{m}^{-3}$ & 890.4 & $847.2^{* *}$ \\
\hline
\end{tabular}

- laboratory analysis results [Oil-club.ru];

** - standard density values (at $\left.15^{\circ} \mathrm{C}\right)$, viscosity and engine oil VI GENESIS CLARITECH 5W-30.

To determine the presence of aromatic hydrocarbons in EO and TC, concentrated sulfuric acid was used [12], [13]. To the volume of $20 \mathrm{ml}$ of liquids was added $0.2 \mathrm{ml}$ of $\mathrm{H}_{2} \mathrm{SO}_{4 \text { finish. }}$ The percentage of acid (by volume) did not exceed $\sim 1 \%$.

As a result of the research, it was established that the engine oil, after the introduction of $\mathrm{H}_{2} \mathrm{SO}_{4 \text { finish }}$ into it, transforms into an emulsion, the color of which does not change during the 15 hours of the experiment (stirring with a magnetic stirrer at $80^{\circ} \mathrm{C}$ ). The $\mathrm{TC}$ under the same experimental conditions does not form an emulsion with $\mathrm{H}_{2} \mathrm{SO}_{4 \mathrm{finish}}$, the liquid acquires a color characteristic of the reaction products of the interaction of aromatic hydrocarbons with sulfuric acid. Consequently, aromatic hydrocarbons are present in the vehicle.

The established differences in motor indicators of EO and TC, demonstrating a different component composition, are reflected in the values of the degree of swelling. In oil having a lower viscosity, tire tread samples swell more (Table 2). The arenas present in the "suprotec" can make some contribution to the increase in the parameter $\alpha$ of the material in contact with the vehicle, since it is known that the degree of rubber swelling significantly depends on the content of these hydrocarbons in oils [14].

Regardless of the state of the rubber, i.e. whether it is in the original or aged state, absorption of liquid molecules by samples is observed. The degree of swelling of the aged 
material is lower than the parameter $\alpha$ of the original tire tread and seal. The hardness of the aged samples increases by $60-120 \%$. Consequently, the frequency of cross-links increases. This leads to a drop in the flexibility of the chains of macromolecules and, accordingly, to a decrease in the number of molecules formed (as a result of thermal movement), commensurate with the size of molecules of liquids, and small intermolecular spaces of rubber [8], [9], [15], [16].

Rubber swelling is associated with the presence of polar and non-polar rubbers in products. So, non-polar rubbers do not dissolve in liquids whose molecules have a dipole moment, polar rubbers partially swell in non-polar solvents [8]. The presented regularity makes it necessary to set up experiments that make it possible to reveal the polar fragments of the structure of rubbers.

To solve this problem, the original and aged tire tread were polarized (in air) in an external constant electric field of $2.0 \times 10^{6} \mathrm{~V} \cdot \mathrm{m}^{-1}$ (blocking electrodes) at a temperature of $70^{\circ} \mathrm{C}$ for 0.3 hours. Next, the objects of study were cooled, without removing the field, to room temperature. The presence of the polarization effect in the samples was monitored by measuring the thermally stimulated shortcircuit currents in the linear heating mode (from 20 to $250^{\circ} \mathrm{C}$ ) of rubber with a speed of $\sim 5-6$ degrees $\min -1$ [17].

It was found that, regardless of the condition of the rubber (aged, not aged tire tread), with linear heating of the samples in the external circuit of the electrometric cell, a short circuit current (SCC) is recorded.

The appearance of SCC is associated with the presence in the volume of the material of dipoles, which, being oriented in the direction of the external electric field, form a space charge [18]. Consequently, the tire tread rubber structure contains polar fragments.

\section{CONCLUSION}

Thus, from the presented results of the experiments and their analysis, it follows that the degree of swelling $(\alpha)$ of aged rubber is lower than the parameter $\alpha$ of the original samples.

Differences in the degree of swelling of the tread in contact with the engine oil and the TC are associated not only with a different composition of oil, but with the presence of aromatic hydrocarbons in the "Suprotec" as well.

Lower than for the tire tread, the $\alpha$ parameters of the seal when the rubber comes in contact with isooctane are explained by the gland rubber composition that is resistant to the effects of oil and gasoline. To establish the peculiarities of rubber swelling, it is necessary to have knowledge of the presence of polar fragments in rubber, since swelling depends not only on the dipole moments of the molecules of liquids (solvents), but on the polarity of the rubber network as well.

\section{REFERENCES}

1. K. B. Piotrovsky and Z. N. Tarasov. Aging and stabilization of synthetic rubbers. M: Chemistry, 1980.

2. E. N. Cherezova, N. A. Mukmeneva, and V. P. Archhareas. Aging and polymer stabilization. Part 1: study guide. Kazan: Kazan publishing house. national research tech nol. University, 2012.

3. B. B. Bobovich. Non-metallic construction materials (structure, properties, application): a training manual. M: FORUM: INFRA-M, 2014.

4. N. P. Kotenko. Rubber and rubber: a training manual for practical exercises and laboratory work for graduate students in the direction of the preparation of Chemical technology. South Russian State Polytechnical University (NPI) named after M.I. Platov. Novocherkassk: YuPGPU (NPI), 2017.

5. T. I. Igumenova, N. L. Kleimenova, and N. O. Savchenko. Research and analysis of the degree of swelling of rubber cuffs reinforced with the addition of fullerene containing filler after exposure to standard fluid. Electronic scientific and technical journal "Youth Scientific Bulletin". No. 1., 2016, pp. 42-51.

6. V. A. Damzen and S. V. Elistratov. The study of the reliability of automobile tires. Scientific and technical journal "Reliability", No 2, 2014, p. 33-42.

7. I. V. Ivanov. Improving the reliability of automotive engines by controlling the tightness of crankshaft lip seals during overhaul. Abstract of dissertation. Volgograd, 2011.

8. L. A. Bergstein. Laboratory Workshop on Rubber Technology: Proc. for the technical schools. 2nd ed., Pererab. L.: Chemistry, 1989.

9. N. I. Avakumova, L. A. Budarin, S. M. Divgu, et al. Workshop in chemistry and physics of polymers. M.: Chemistry, 1990.

10. GOST R ISO 1817-2009. Rubber. Determination of resistance to liquids. M.: Standardinform, 2011.

11. V. N. Polovinkin, V. F. Gorshkov, Yu. G. Lavrov, O. M. Rumyantseva, N. A. Semenova, Kussai Al Dayub, $\mathrm{Yu}$. V. Volkov, T. S. Vinogradova. The study of the influence of the tribotechnical composition «suprotec» on the performance of the internal combustion engine. St. Petersburg, 2004.

12. G. I Deryabina, O. N. Nechaev, I. A. Potapova. Workshop on organic chemistry. Part II. Reactions of organic compounds [Text]: in 2 parts. Samara: University Publishing House, 2007.

13. E. E. Gilbert. Sulfonation of organic compounds. M.: Chemistry, 1969.

14. Oil products (reference book). M.: Publishing House «Chemistry», 1966.

15. A. B. Lukyanov. Physical and colloidal chemistry: A textbook for technical schools. 2nd ed. reclaiming and add. M.: Chemistry, 1988.

16. E. N. Cherezova, N. A. Mukmeneva, V. P. Archireev. Aging and stabilization of polymers. Kazan: Kazan publishing house, 2012.

17. A. A. Khodyakov, M. M. Bendik, V. S. Antipenko. Polarization of rubber tire tread rubber samples. Proceedings of the international conference and the Russian scientific school «System problems of quality, mathematical modeling, information and electronic technologies.». M.: MSTU «MAMI», 2010.

18. Yu. A. Gorokhovatsky, G. A. Bordovsky. Thermal activation current spectroscopy of high-resistance semiconductors and dielectrics. M.: Nauka, 1991. 